\title{
CARM1 is heterogeneous in mouse four-cell embryo and important to blastocyst development
}

\author{
Hongzheng Sun*, Jianmin Su*, Teng Wu, Fengyu Wang, Jian Kang, Jingcheng Zhang, \\ Xupeng Xing, Yuyao Cheng and Yong Zhang \\ Key Laboratory of Animal Biotechnology of the Ministry of Agriculture, College of Veterinary Medicine, Northwest \\ A\&F University, Yangling, Shaanxi Province, China \\ Correspondence should be addressed to Y Zhang; Email: zhy1956@263.net
}

*(H Sun and J Su contributed equally to this work)

\begin{abstract}
Coactivator-associated arginine methyltransferase 1 (CARM1) is a type I arginine methyltransferase that methylates the arginine residues of histone and nonhistone. Carm 1 regulates various cellular processes, including transcriptional regulation, mRNA processing, cellular proliferation, and differentiation. Blastomeres with high Carm 1 expression levels show cleavage tendency to inner cell mass (ICM) in mouse embryos. However, details about the factors for CARM1 distribution in mouse early embryos and the role of Carm 1 in blastocyst development remain unclear. Here, the endonuclear distribution of CARM1 protein was heterogeneous between blastomeres from the late four-cell stage to the blastocyst stage. The heterogeneity of CARM1 distribution in blastomeres at the late four-cell stage was randomly obtained from two-cell stage embryos. From the four-cell stage to morula, CARM1 in individual blastomere remained heterogeneous. In the blastocyst stage, CARM1 protein level in ICM was much higher than that in trophoblast. We found that microRNA (miRNA) miR-181a is an important regulator for Carm1 distribution at the late four-cell stage. The ratio of heterogeneous embryos was reduced in all the embryos when miR-181a was inhibited. CARM1 inhibition reduced the level of symmetrical histone $\mathrm{H} 3$ arginine-26 dimethylation and impaired blastocyst development. Silencing Carm 1 reduced cell number and increased cell apoptosis at the blastocyst stage. These results show a CARM1 heterogeneous distribution from the four-cell embryos to the blastocysts. miR-181a regulates the control of CARM1 heterogeneous distribution in the four-cell-stage embryos, and CARM1 is an important protein in regulating blastocyst development.
\end{abstract}

Reproduction (2020) 159 91-104

\section{Introduction}

Coactivator-associated arginine methyltransferase 1 (CARM1, also known as PRMT4) belongs to the type I PRMT family that catalyzes the transfer of methyl groups from S-adenosyl-L-methionine to the $\mathrm{N}$ of arginine residues on $\mathrm{R} 17$ and $\mathrm{R} 26$ sites in histone $\mathrm{H} 3$ and nonhistone proteins, including SRC-3, CBP/p300, RNA pol II, and Sox2 (Schurter et al. 2001, Xu et al. 2001, Yadav et al. 2003, Sims et al. 2011, Zhao et al. 2011). Carm1 regulates various cellular functions, including mRNA processing and stability, transcription, and translation (Ma et al. 2001, Bedford \& Richard 2005, Cook et al. 2006). Carm 1 overexpression is associated with various cancers, such as breast tumors, prostate adenocarcinomas, and liver cancers, due to its methylation on histone- and cancer-associated transcription factors, including NF-kB, p53, and E2F1 (Hong et al. 2004, Bedford \& Clarke 2009, Cheng et al. 2013, Osada et al. 2013). Therefore, CARM1 can be a potential target for cancer therapy. CARM1 is closely related to the pluripotency in embryonic stem (ES) cells and transactivates stem-associated transcription factors, including Oct4 and Sox2 (Wu et al. 2009, Xu et al. 2013). When Carm 1 is overexpressed, ES cells can increase its resistance to differentiation; otherwise, ES cells will differentiate into specific lineages when Carm 1 is depleted (Wu et al. 2009). Morula transition to blastocyst is associated with cell differentiation and blastomere fate decision. However, the mechanism of the effect of Carm 1 on this process is poorly understood.

Blastomeres undergo major changes in developmental potency during mouse preimplantation embryonic development. The heterogeneity of embryonic blastomeres arises as early as the four-cell stage, thereby exhibiting differences in developmental potency (Fujimori et al. 2003, Piotrowska-Nitsche et al. 2005, Torres-Padilla et al. 2007). Meanwhile, the spatial arrangement of an individual blastomere at the four-cell stage affects epigenetic modifications, transcriptional activity, and embryonic-abembryonic axis in blastocysts (Piotrowska-Nitsche \& Zernicka-Goetz 2005, TorresPadilla et al. 2007). Through epigenetic marker analysis, 
Torres-Padilla et al. (2007) revealed that H3R26me2, which is correlated with cell fate and potency, is heterogeneous at the four-cell mouse embryo stage. The blastomere with overexpressed Carm 1 contributes to the high H3R26me2 level and directs its potency to the inner cell mass (ICM). Conversely, the blastomere that is potentially part of the differentiation phenotype has low H3R26me2 and CARM1 levels. CARM1 regulates lineage specification by suppressing cell polarity and reducing the expression of $\mathrm{Cdx} 2$, which is a trophoderm-specific gene (Parfitt \& Zernicka-Goetz 2010). Carm 1-knockout embryos are reduced in size (Yadav et al. 2003). In addition, mice with Carm 1 depletion die perinatally and show defective $\mathrm{T}$ cell and lung development and adipogenesis (Yadav et al. 2003, 2008, Kim et al. 2004, 2010). Therefore, Carm 1 is important in modulating the developmental potency of blastomeres and predisposing the differentiation of fetal tissues. miRNAs are 21-23 nucleotide noncoding RNAs that are generally base-paired with the 3'-UTRs of their target mRNAs to induce degradation and inhibit their translation. miRNAs are involved in a broad range of biological processes, such as embryonic development, cell proliferation, apoptosis, and stem cell renewal and pluripotency (Sinkkonen et al. 2008, Goossens et al. 2013, Chen et al. 2017, Dernowsek et al. 2017). Tang et al. (2007) reported that maternally inherited miRNAs are essential to mouse embryonic development at the earliest stages following Dicer maternal knockdown (KD). The effect of individual miRNA on embryonic development has been widely discussed (Renthal et al. 2010, Liu et al. 2012, Zhang et al. 2015, Tan et al. 2016). miR-181a, which is closely related to cell proliferation, development, and cancer, is a member of the miR-181 family (Zhang et al. 2013, 2018, Xu et al. 2014). Xu et al. (2013) reported that miR-181c targets Carm 13 '-UTR to promote human embryonic stem cell differentiation. However, the mechanism of the effect of miRNAs on the epigenome of an early embryo remains unclear. Whether miRNAs participate in the regulation of mouse embryonic heterogeneity also needs to be elucidated.

In this report, Carm 1 heterogeneity is shown at the mouse four-cell-stage embryos and is not predetermined in two-cell embryos. miR-181a is a key factor for regulating the heterogeneous distribution of Carm 1 at the four-cell stage. As an arginine methylase, Carm 1 is responsible for H3R26me2s construction. As a transcription factor, it is essential for normal blastocyst formation and hatching. These findings indicate the clear localization and function of Carm 1 in mouse preimplantation embryos.

\section{Materials and methods}

\section{Embryo work}

Kunming strain mice used in this study were purchased from the Experimental Animal Center of $\mathrm{Xi}^{\prime}$ an Jiaotong University

Reproduction (2020) 159 91-104
(Xi'an, China). The mice were maintained on a 12/12 h light/ dark cycle and $50-70 \%$ humidity with free access to food and water at the Laboratory Animal Facility of the College of Veterinary Medicine, Northwest A\&F University. All animal works and experiments were approved by the Animal Care Commission of the College of Veterinary Medicine, Northwest A\&F University.

Female mice aged 6-8 weeks were superovulated by an intraperitoneal injection of $5 \mathrm{IU}$ pregnant mare serum gonadotropin, followed by an intraperitoneal injection of 5 IU human chorionic gonadotropin (hCG) after $48 \mathrm{~h}$. Female mice were individually mated with Kunming male mice after being injected with hCG. Zygotes enclosed in cumulus masses were released from the ampullae, and cumulus cells were removed by digestion with $\mathrm{M} 2$ media containing $1 \mathrm{mg} / \mathrm{mL}$ hyaluronidase (Sigma, H3506) for $2-3$ min at $37^{\circ} \mathrm{C}$. Embryos were collected and cultured in fresh KSOM medium (Caisson, IVL04) at $37^{\circ} \mathrm{C}$ under $5 \% \mathrm{CO}_{2}$. Lastly, two-cell, four-cell, eightcell, morula, and blastocyst-stage embryos were collected after 22-26, 48-50, 60-65, 70-75, and 96-100 h of culture, respectively. The zona pellucida was removed using Tyrode's solution (Sigma). Embryos were treated at two-cell or morula stage with a chemical inhibitor against CARM1 (Millipore) to inhibit CARM1 activity, and the concentration of CARM1 inhibitor was selected according to the published article (Goolam et al. 2016).

\section{$R N A$ isolation and quantitative real-time PCR}

Pooled embryos ( $n=100$ embryos per sample) were lysed with Cells-to-Signal ${ }^{\mathrm{TM}}$ Kit (Ambion Co., Austin, TX, USA) according to the manufacturer's instructions, and first-strand cDNA was directly synthesized with SuperScript ${ }^{\circledR}$ III CellsDirect cDNA Synthesis Kit (Invitrogen) according to the manufacturer's instructions. After synthesis, we used the ABI StepOnePlus PCR system (Applied Biosystems) to perform the qRT-PCR experiment with the first-strand cDNAs. The results were normalized to PPIA mRNA level. Data were expressed as fold change $=2^{-\Delta \Delta C t}$. Each reaction was run in triplicate with at least three independent replicates.

Mature miRNA samples ( $n=100$ embryos per sample) were reverse-transcribed with miScript II RT (Qiagen). To quantify the miRNA, we also examined the mature miRNA expression through qRT-PCR by using miScript SYBR Green PCR Kit (Qiagen) according to the manufacturer's instructions. The expression level of each miRNA species was normalized to that of U6. The primer sequences are listed in Supplementary Table 1 (see section on supplementary materials given at the end of this article).

\section{Cell culture}

Mouse NIH/3T3 and F9 cells were maintained and grown in Dulbecco's modified Eagle's medium (Gibco) supplemented with $10 \%$ fetal bovine serum. All cell media were supplemented with $50 \mathrm{U} / \mathrm{mL}$ penicillin (Invitrogen) and $50 \mu \mathrm{g} /$ $\mathrm{mL}$ streptomycin (Invitrogen). The cells were cultured at $37^{\circ} \mathrm{C}$ in a humidified $5 \% \mathrm{CO}_{2} / 95 \%$ air incubator. 


\section{Western blot analysis}

Total cell lysates were prepared in a $1 \times$ sodium dodecyl sulfate buffer (Sun et al. 2018). Different cells were lysed with radioimmunoprecipitation assay buffer (Beyotime, P0013B). Proteins were electrophoresed on 12\% acrylamide gels and transferred to PVDF membranes (Millipore). Membranes were blocked in 5\% nonfat milk/Tris-buffered saline Tween-20 for $4 \mathrm{~h}$ at room temperature (RT) and then incubated with the primary antibody overnight at $4{ }^{\circ} \mathrm{C}$. Primary antibodies are shown in Supplementary Table 2. All secondary antibodies were purchased from Beyotime Company (Beyotime, China).

\section{Immuonoflourescence staining}

Cells and pooled embryos were fixed in 4\% paraformaldehyde in phosphate-buffered saline (PBS) for $30 \mathrm{~min}$, washed, and permeabilized in PBS containing 0.2\% Triton X-100 for 15 min at RT. After treatment with $5 \%$ bovine serum albumin (BSA) in PBS for $2 \mathrm{~h}$ at RT, the samples were incubated with the primary antibody diluted in PBS containing $1 \%$ BSA overnight at $4^{\circ} \mathrm{C}$, washed twice, and incubated with the corresponding secondary antibodies for $2 \mathrm{~h}$ at RT. Subsequently, nuclei were stained with DAPI (Beyotime, C1005) for 5 min. Primary antibodies used here are shown in Supplementary Table 2. All secondary antibodies were purchased from Beyotime Company (Beyotime). The samples were observed under a Nikon eclipse Ti-S (Nikon) or a Zeiss Axio Observer D1 microscope (Carl Zeiss, Inc.). Multiple images were exposed to IMAGEJ for processing, intensity measurements, and cell counting. Fluorescence intensity was quantified by normalizing to DAPI by using the built-in IMAGEJ function. Data were normalized with respect to background levels.

\section{SiRNA, miRNA, and mRNA microinjection}

The miRNA mimic, miRNA inhibitor, and mouse Carm 1specific siRNA were diluted in nuclease-free water to final concentrations of $800 \mathrm{nM}, 25 \mu \mathrm{M}$, and $40 \mu \mathrm{M}$, respectively. The aliquots of $5-10 \mathrm{pl}$ of the siRNA/miRNA were microinjected into the cytoplasm of mouse zygotes in M2 medium (Sigma-Aldrich, M7167) using an Eppendorf micromanipulator under a Leica inverted microscope and then cultured in fresh KSOM medium. Controls were injected with the negative control siRNA. Zygotes cultured for $24 \mathrm{~h}$ (two-cell stage) were collected to detect knockdown efficiency by qRT-PCR. siRNA sequence used to silence Carm 1 is as follows: 5'-CCUGGUGAAGAGUAACAAUdTdT-3'.

Enhanced fluorescent green protein (EGFP) cDNA was cloned into T7-driven vectors and synthesized using the mMESSAGE mMACHINE T7 Ultra Kit (Life Technologies) according to the manufacturer's instruction. The storage concentration of each mRNA was optimized to $800 \mathrm{ng} / \mu \mathrm{L}$. For two-cell embryo injection, 5-10 pl of EGFP mRNA was randomly injected into one two-cell embryo blastomere. Then, two-cell embryos were cultured in fresh KSOM medium.

\section{Terminal deoxynucleotidyl transferase dUTP nick end labeling assay}

We carried out apoptosis assays to detect apoptotic cells in 4-day blastocysts using the DeadEnd Fluorometric TUNEL System (Promega) in accordance with the methods of a previous study (Su et al. 2012).

\section{Blastocyst outgrowth culture}

Here, $0.1 \%$ gelatin was pipetted into wells of a 48 -well plate, which was then placed in an incubator for $10 \mathrm{~min}$. Subsequently, the gelatin was discarded and left at RT for $10 \mathrm{~min}$. Then, the stem cell culture medium containing LIF was added to the wells of the 48-well plate and incubated to equilibrate the medium. The zona pellucida (ZPs) of the 4-day blastocysts were removed by incubating them for 10-30 s in $100 \mu \mathrm{L}$ of prewarmed Tyrode's solution until the ZPs were dissolved, as observed under a microscope. The blastocysts were immediately transferred to a wash dish containing MEMHEPES. Then, one blastocyst was transferred to a well of the prepared blastocyst outgrowth culture plate and then cultured at $37^{\circ} \mathrm{C} / 5 \% \quad \mathrm{CO}_{2}$ for $72 \mathrm{~h}$. The blastocysts were examined under a microscope after $72 \mathrm{~h}$ culture.

\section{Statistical analysis}

Each experiment was repeated at least thrice. In embryonic development experiments, the number of examined embryos was indicated $(n)$. The data were presented as means \pm S.D. Student's $t$-test was used to compare the two groups. We used SPSS, version 19.0 (IBM Corporation) for analyses. Significance was accepted at $P<0.05$.

\section{Results}

\section{Expression pattern of Carm1 mRNA in early embryos}

We examined the mRNA expression levels of Carm 1 in mouse preimplantation embryos by qRT-PCR analysis to reveal the expression profile of Carm 1. During the preimplantation embryonic stage, Carm1 was predominantly expressed at two-cell stage, and the level decreased from the four-cell stage (Fig. 1A). Meanwhile, the Carm 1 expression level in the germinal vesicle and meiosis II stage was significantly lower than that in the one-cell stage. Carm 1 was activated at the zygote stage. We then detected the Carm 1 expression level between the early one-cell-stage embryos and late one-cell-stage embryos (Fig. 1B). Carm 1 expression increased at the late one-cell stage possibly coinciding with the minor wave of zygotic genome activation (Hamatani et al. 2004).

\section{CARM1 protein distribution was heterogeneous at late four-cell stage}

CARM1 distribution at each stage of mouse embryo preimplantation has not been elucidated well to date. 

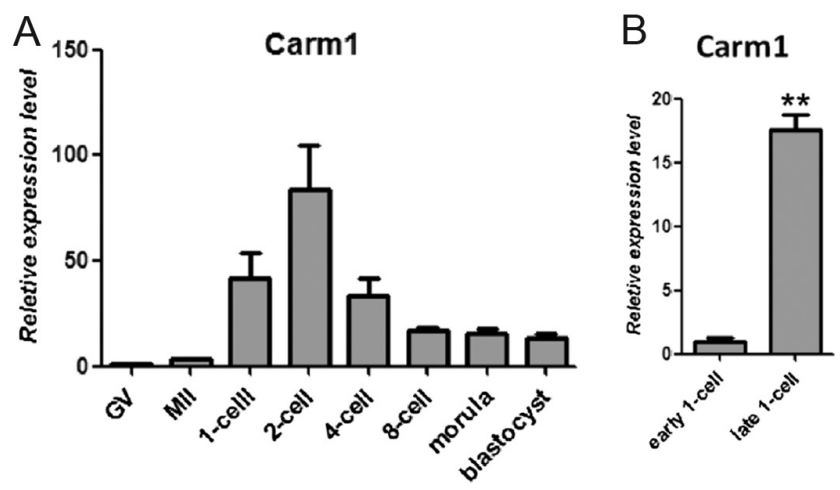

Figure 1 Expression pattern of Carm 1 in mouse preimplantation embryos. (A) qRT-PCR analysis of Carm 1 was performed in GV, MII oocytes, zygotes, two-cell embryos, four-cell embryos, eight-cell embryos, morula, and blastocyst. (B) mRNA level of Carm 1 in early one-cell stage and late one-cell stage. Bar indicates the S.D. ${ }^{*} * P<0.01$.

We analyzed the CARM1 protein levels from the zygote stage to the blastocyst stage via immunostaining. As shown in Fig. 2A, CARM1 showed mainly nuclear distribution, except at the meiosis II stage. From zygote to early four-cell stage, the CARM1 protein was evenly distributed in the nucleus at each stage. From the beginning of the late four-cell stage, the CARM1 protein in the nucleus was heterogeneously distributed. Meanwhile, the CARM1 protein in the cytoplasm of each stage was almost equally distributed. Thus, the CARM1 ratio in the nucleus and cytoplasm (Nucl./Cyto.) was adopted for the analysis of asymmetry. The Nucl./ Cyto. ratio in preimplantation is shown in Fig. 2B. In the blastocyst stage, the CARM1 protein level in the ICM was higher than that in the trophoblast (Supplementary Fig. 1A). The CARM1 heterogeneity at the early and late four-cell stages was analyzed and is shown in Fig. 2C. At the early four-cell stage, a small part of embryos $(23.1 \%$, $n=26)$ displayed heterogeneity in CARM1 distribution. After the development for $10-12$ h, $72.7 \%(n=44)$ of embryos revealed CARM1 distribution heterogeneity in the nucleus. According to the data of single-cell sequencing (Goolam et al. 2016), we analyzed the mRNA levels of the four blastomeres at the four-cell stage. The expression pattern of Carm 1 mRNA was consistently highly variable, and the expression level between the highest and lowest expressing blastomeres across all four-cell embryos greatly varied (Fig. 2D; $n=40$ cells, 10 embryos). In most cases, at least one blastomere in each embryo expressed an extremely low or no Carm 1 mRNA level (Fig. 2E; Goolam et al. 2016). Then, we examined the protein level in each blastomere of a four-cell embryo (Fig. 2F). The cellular heterogeneity in CARM1 protein level was consistent with its mRNA expression level (Fig. 2G; $n=10$ ). The CARM1 protein expression was also variable at the eight-cell stage, and the statistical results are shown in Supplementary Fig. 1B.

\section{Heterogeneous CARM1 distribution was not predetermined in two-cell embryos}

We performed microinjection experiments to trace the dynamic CARM1 distribution from two-cell stage embryos to provide additional insights into CARM1 heterogeneity in four-cell stage blastomeres. EGFP mRNA was randomly injected into a one blastomere of the two-cell stage embryos (Fig. 3A). The CARM1 protein distribution in four-cell-stage blastomeres with or without EGFP was analyzed by IF. Embryos with two blastomeres with high CARM1 expression are shown in Fig. 3B (rows two and three; 30.6\%, $n=85$ ). Row 4 represents the situations that two blastomeres with high CARM1 expression came from different blastomeres of two-cell-stage embryos $(45.9 \%, n=85)$. The results demonstrated the random Carm 1 source from two-cell embryos. Torres-Padilla et al. (2007) reported that Carm 1 overexpression in a two-cell blastomere can result in the contribution of that cell predominantly to the ICM of the blastocyst stage. Then, two-cell-stage embryos with one blastomere injected with EGFP mRNA were developed into the blastocyst stage. As shown in Fig. 3C, the EGFP distribution in the blastocyst can be divided into the following four patterns: evenly distributed, half of the blastocyst, mainly in ICM, and mainly in TE. The proportion of each pattern is shown in Fig. 3C. The Carm1 expression level in the ICM of the blastocyst was considerably higher than that in TE (Supplementary Fig. 1A). Thus, the EGFP distribution injected into one of the two-cell blastomeres is inconsistent with the CARM1 distribution. Similar result was obtained when embryos with one two-cell stage blastomere was injected with EGFP developed into the morula stage (Fig. 3D). The blastomere injected with EGFP did not contribute to the inner or outer cells only.

\section{miRNA-181a regulated Carm1 expression and heterogeneous distribution}

Considering the dynamic changes in the CARM1 protein level during the four-cell embryonic development, we then quantified the mRNA levels of Carm 1 between the early and late four-cell embryos. As shown in Fig. $4 \mathrm{~A}$, the Carm 1 mRNA level in early four-cell embryos was higher than that in the late four-cell embryos. Xu et al. (2013) reported that miR-181c targets Carm 1 3'-UTR to promote human ES cell differentiation. The $3^{\prime}$-UTR sequences were also mostly conserved in different species (Fig. 4B). This result prompted us to consider whether miR-181 regulates Carm1 expression in mouse embryos. The mature transcripts of the four members of the miR-181 family were quantified from one- to eight-cell embryos (Fig. 4C). Only the miR-181a level significantly increased from one- to eight-cell embryos. This outcome was consistent with the decrease in Carm 1 mRNA level from one- to eight-cell embryos. The miR-181a level was higher at the late stage than 

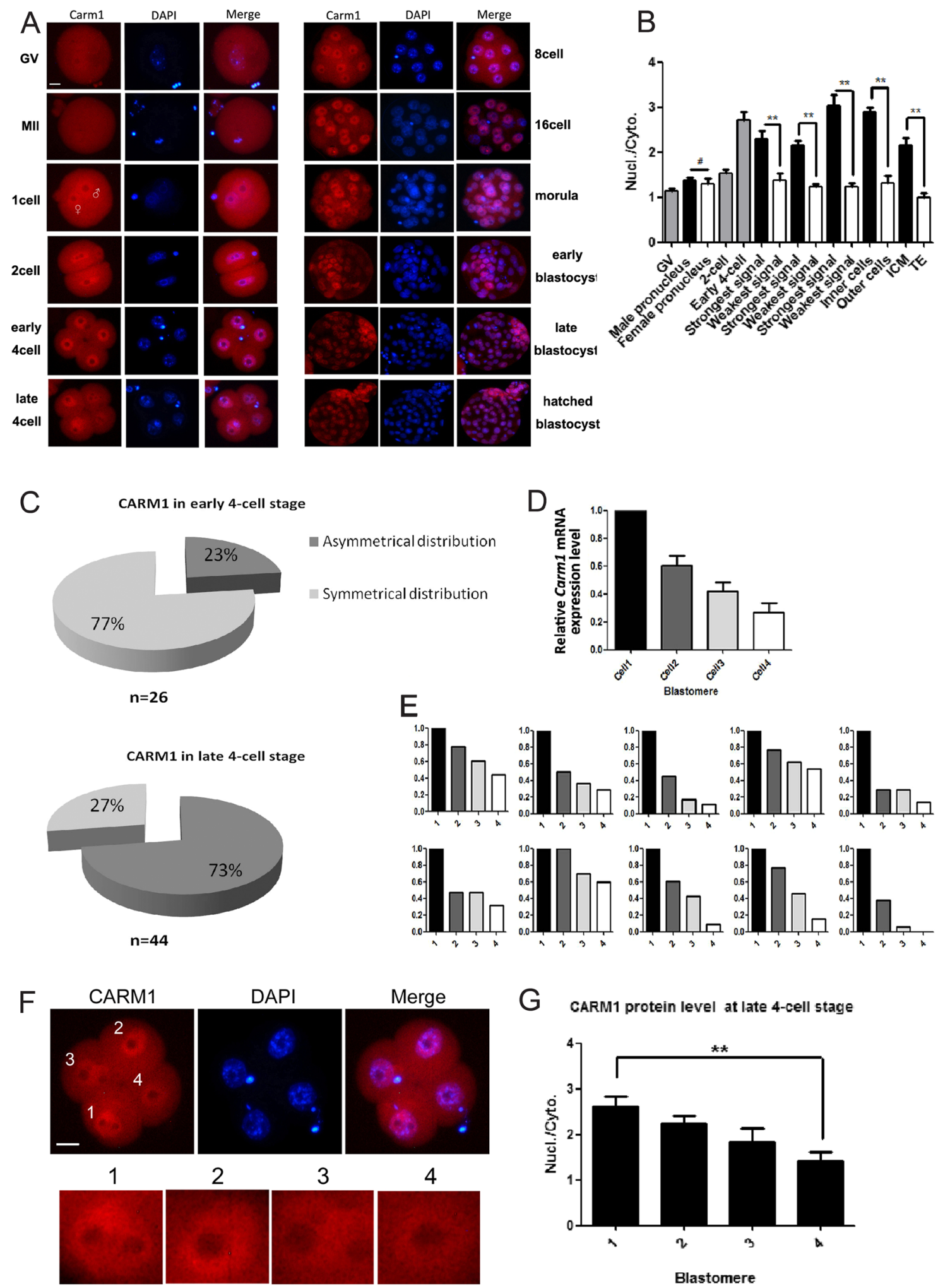

Figure 2 CARM1 heterogeneity analysis at four-cell stage. (A) Freshly collected oocytes and various early embryos were processed for immunostaining with Carm 1. Scale bar $=20 \mu \mathrm{m}$. (B) Nuclear/cytoplasm (Nucl./Cyto.) ratio of Carm 1 fluorescence intensity at each embryonic stage. ${ }^{* *} P<0.01,{ }^{\sharp} P>0.05$. Error bars represent S.D. (C) Proportion of heterogeneous distribution of Carm1 in early $(n=26)$ and late $(n=44)$ four-cell stage embryos. (D) Average relative Carm 1 mRNA levels in four-cell embryos. (E) Relative Carm 1 mRNA expression in all individual four-cell embryos. (F) Carm 1 immunofluorescence in late four-cell embryos. Scale bar $=20 \mu \mathrm{m}$. (G) Fluorescence analysis of Carm 1 in Nucl./Cyto. ratio per individual four-cell embryo blastomere $(n=10)$. Error bars represent S.D. ${ }^{* *} P<0.01$. 
A

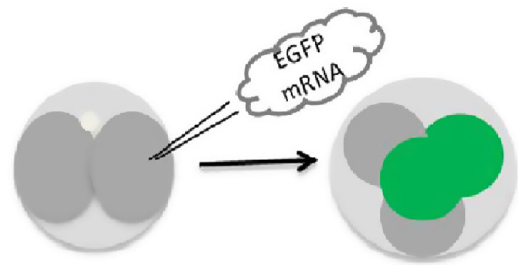

B
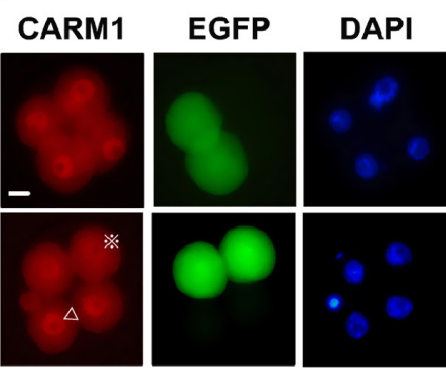

Merge
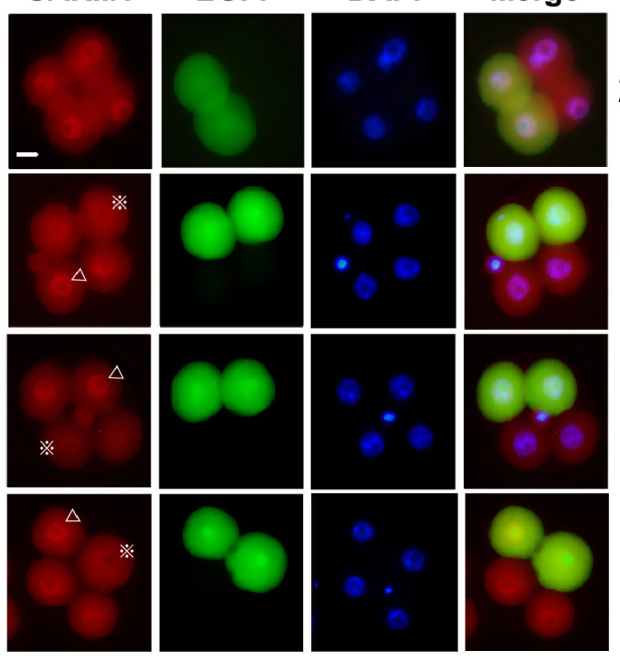

$20 / 8523.5 \%$

C

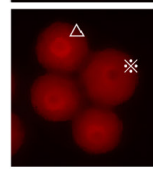

\begin{tabular}{c|c|c|}
$\begin{array}{c}\text { Two blastomeres with } \\
\text { higher CARM1 level }\end{array}$ & $\begin{array}{c}\text { From one blastomere of 2- } \\
\text { cell embryo }\end{array}$ & $\begin{array}{c}\text { From different blastomere } \\
\text { of 2-cell embryo }\end{array}$ \\
\hline Ratio(\%) & $\mathbf{3 0 . 6 ( 2 6 / 8 5 )}$ & $\mathbf{4 5 . 9 ( 3 9 / 8 5 )}$ \\
\hline
\end{tabular}

$11 / 8512.9 \%$

$15 / 8517.6 \%$

$39 / 8545.9 \%$

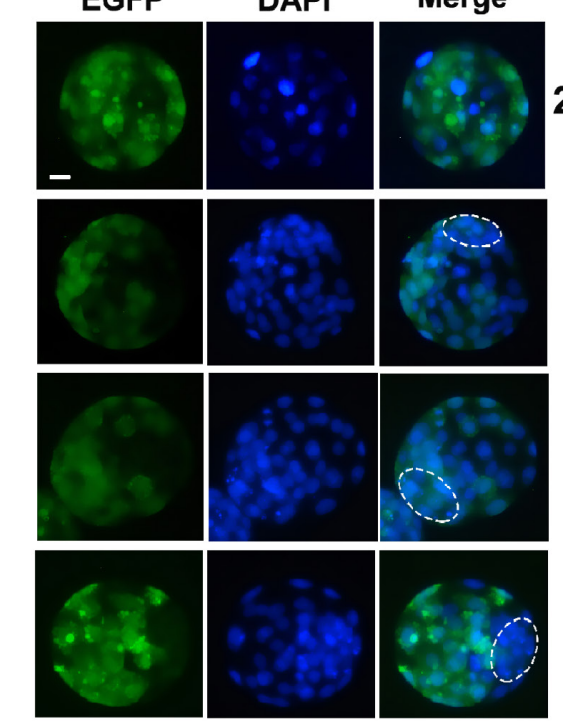

$24 / 3666.7 \%$

$6 / 3616.7 \%$

$2 / 36 \quad 5.5 \%$

\begin{tabular}{|c|c|c|c|c|}
\hline Distribution & $\begin{array}{c}\text { Evenly } \\
\text { distribution }\end{array}$ & $\begin{array}{c}\text { Half of the } \\
\text { blastocyst }\end{array}$ & Mainly in ICM & Mainly InTE \\
\hline Ratio (\%) & 66.7 & 16.7 & 5.5 & 11.1 \\
\hline
\end{tabular}

\section{Bright Field}
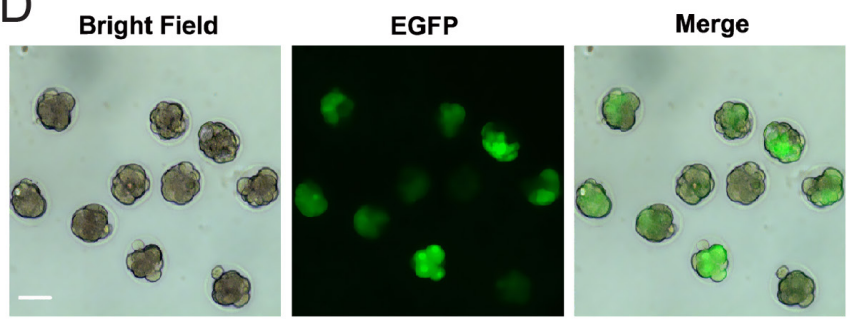

Figure 3 Developmental potential of one blastomere in two-cell embryo. (A) Diagram showing the experiment design. A randomly selected single two-cell blastomere was microinjected with EGFP mRNA. (B) Embryos injected with EGFP developed at the four-cell stage. Analysis of Carm 1 heterogeneity from two-cell stage embryos. The first row represents Carm 1 that was evenly distributed in the four-cell stage embryos $(23.5 \%, n=85)$. The second and third rows represent the two blastomeres with low $(12.9 \%, n=85)$ or high $(17.6 \%, n=85)$ Carm 1 expression coming from the same blastomere of the two-cell stage embryos. The remaining four-cell embryos represent the two blastomeres with high or low Carm 1 expression coming from two different blastomeres of two-cell-stage embryo (line four; $45.9 \%, n=85$ ). Arrowheads indicate the highest blastomere expression. Asterisks indicate the lowest blastomere expression. Scale bar $=20 \mu \mathrm{m}$. (C) Representative blastocysts from the GFP-injected embryos. The ICM position is indicated with a dashed line. Scale bar $=20 \mu \mathrm{m}$. (D) Representative morulas from the GFP-injected embryos. Scale bar $=100 \mu \mathrm{m}$.

that at the early stage of four-cell embryos (Fig. 4D). Subsequently, we constructed the luciferase reporter vectors that have either wild-type (wt) or a mutant (mut) 3'-UTR of Carm 1, with three-point mutations in the seed sequences of the predicted miR-181a-binding sites as the negative control (Fig. 4E). The two resulting constructs were cotransfected with a miR-181a mimic into the mouse cell line $\mathrm{NIH} / 3 \mathrm{~T} 3$. The luciferase activities significantly decreased after the miR-181a coexpression with the Carm 1 wt 3'-UTR compared with the negative control (Fig. 4F). The endogenous Carm 1 mRNA level was also suppressed in response to miR181a mimic and enhanced in response to miR-181a inhibitor in mouse embryos (Fig. 4G). As demonstrated earlier, miR-181a directly targeted Carm 1 3'-UTR sequences and promoted Carm 1 mRNA degradation to some extent. We performed immunostaining analysis to determine whether miR-181a affects CARM1 protein 


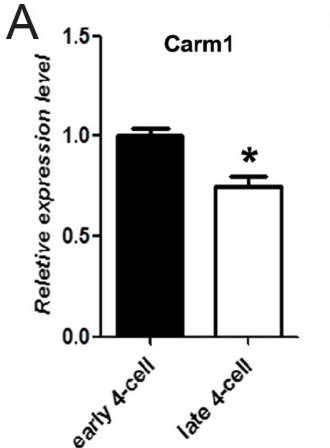

B

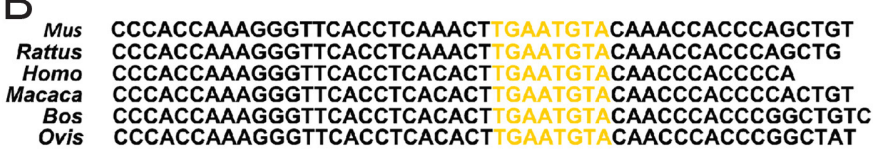

E mmu-miR-181a $\quad 3$ ' UGAGUGGCUGUCGCAACUUACAA $\mathbf{5}^{\prime}$ \| | || || carm1 3' UTR WT 5'...GGUUCACCUCACACUUGAAUGUA....3' carm1 3'UTR MUT 5'...GGUUCACCUCACACUUCACUCUA...3'
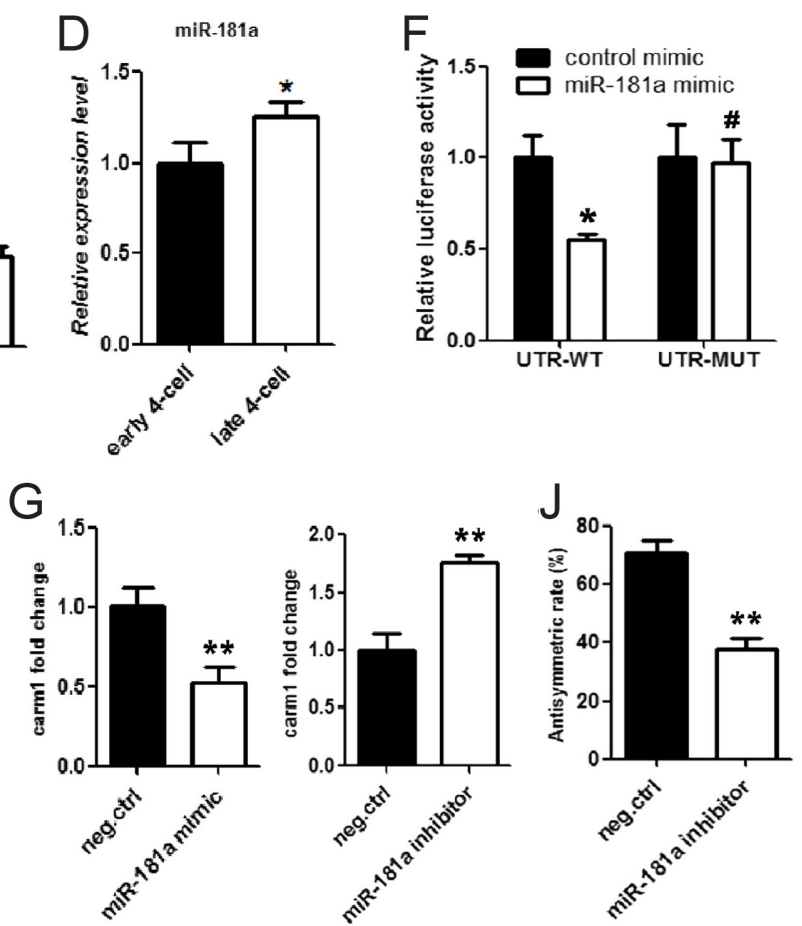

Figure 4 miR-181a directly regulated Carm 1 expression. (A) Carm 1 expression levels at the early and late four-cell stages. Error bars represent S.D. ${ }^{*} P<0.05$. (B) $3^{\prime}$-UTR sequence of Carm 1 targeted by miR-181a was conserved in different species. (C) Expression levels of miR-181 family from zygote to eight-cell stage. Error bars represent s.D. (D) Expression levels of miR-181a in the early and late four-cell stages. Error bars represent S.D. ${ }^{*} P<0.05$. (E) Consequential pairing of miRNA-181a and its target binding sites in wt or mut Carm1 3'-UTR are shown. (F) Relative luciferase activity in NIH/3T3 cells cotransfected with miR-181a and reporter constructs containing wt or mut Carm $13^{\prime}-$ UTR. ${ }^{*} P<0.05$, ${ }^{\sharp} P>0.05$. (G) Relative Carm 1 mRNA levels in embryos were determined by qRT-PCR after injection with miR-181a mimic. Bars indicate the s.D. $* * P<0.01$. (H) Carm1 protein levels in four-cell stage embryos were detected by immunostaining after the injection with miR-181a mimic or inhibitor. Scale bar $=20 \mu \mathrm{m}$. (I) Carm 1 immunofluorescence in late four-cell embryos injected with miR-181a $(n=10)$ or control inhibitor $(n=8)$. Fluorescence was quantified and normalized to the nucleus with the strongest staining per individual four-cell embryo. Scale bar $=20 \mu \mathrm{m}$. Bars indicate the S.D. (J) Analysis of the Carm 1 heterogeneity between embryos injected with miR-181a inhibitor $(n=74)$ and the control group $(n=67)$. Error bars represent S.D. ${ }^{* *} P<0.01$.

level or its heterogeneity in the late four-cell stage embryos. The result revealed that the CARM1 protein levels of the four-cell embryos decreased in response to
miR-181a mimic injection and increased in response to miR-181a inhibitor injection (Fig. 4H). Meanwhile, the rate of CARM1 heterogeneity significantly decreased in 
the miR-181a inhibitor-injected four-cell embryos (Fig. $4 \mathrm{I}$ and $\mathrm{J} ; 71.0 \pm 4.0 \%$, the control group; $38.0 \pm 3.8 \%$, the miR-181a inhibitor-injected group). These results suggested that miR-181a was a key regulator for Carm1 expression and heterogeneous distribution in four-cell stage mouse embryos.

\section{Symmetric H3R26 dimethylation was catalyzed by CARM1}

CARM1 is a type I PRMT that catalyzes asymmetrically dimethylated protein substrates on arginine residues (Chen et al. 2000, Ma et al. 2001, Di Lorenzo \& Bedford 2011). CARM1 catalyzed the asymmetrical dimethylation R26 site in histone H3 (H3R26me2a) (Schurter et al. 2001, Zhang et al. 2017). However, the enzyme responsible for the construction of symmetrical dimethylation R26 site in histone H3 (H3R26me2s) remains unclear. The difference between H3R26me2a and H3R26me2s is shown in Supplementary Fig. 2A. Here, we further investigated whether H3R26me2s is catalyzed by CARM1. First, we performed IF to reveal H3R26me2s distribution in early mouse embryos (Fig. $5 \mathrm{~A})$. The heterogeneous distribution of H3R26me2s was detected at the four-cell stage embryos, not in two-cell stage embryos (Supplementary Fig. 2B and C). Considering the similar distribution between Carm1 and H3R26me2s in four-cell stage embryos, we next performed Western blot and IF using two cell lines to confirm whether H3R26me2s was catalyzed by CARM1. CARM1-specific inhibitor 1-benzyl-3,5-bis-(3bromo-4-hydroxybenzylidene) piperidin-4-one (called 'inhibitor') was used to inhibit the enzymatic activity of CARM1 (Supplementary Fig. 2D) (Goolam et al. 2016). At the cellular level, CARM1 inhibitor potently inhibited H3R26me2s (Fig. 5B and C). Through Carm1 overexpression and silencing experiments, we also found that CARM1 is responsible for H3R26me2 construction (Fig. 5D). Then, we treated the two-cell embryos with CARM1 inhibitor. All embryos treated with 4.5 or 9.0 $\mu \mathrm{M}$ inhibitor were arrested at the two-cell stage (Fig. 5E). Subsequently, we treated the morula embryos with $9 \mu \mathrm{M}$ inhibitor for $24 \mathrm{~h}$. Approximately half of the embryos were arrested at the morula stage, and the remaining embryos developed into the early blastocyst stage (Fig. 5E). Meanwhile, the embryos treated with dimethyl sulfoxide (DMSO) can develop into the late blastocyst stage. We also treated early two-cell stage embryos with an inhibitor for $16 \mathrm{~h}$ to collect the embryos. Then, the late two-cell embryos treated with an inhibitor or DMSO was collected for the analysis of H3R26me2s level. Meanwhile, early blastocysts treated with an inhibitor or DMSO underwent the same analysis. As shown in Fig. $5 \mathrm{~F}$, the H3R26me2s level decreased in inhibitor-treated embryos, especially in the two-cell embryos. (O'Brien et al. 2010) reported that embryos with Carm 1 loss can survive until birth and respond to stimulus. Conversely, our results showed that embryos treated with CARM1specific inhibitor almost arrested at the two-cell or morula stage. The difference between our results and the findings of O'Brien's study was significant. We predicted that CARM1 inhibitor can affect cell survival in addition to inhibiting H3R26me2s. At the cellular level, some $\mathrm{NIH} / 3 \mathrm{~T} 3$ cells exhibited morphotype change when treated with CARM1 inhibitor (Supplementary Fig. 2E). CARM1 inhibitor treatment resulted in the change in nuclear organization in cells (Supplementary Fig. 2F). Similar results that are consistent with AMI-1 treatment, a specific inhibitor of arginine methylation (Supplementary Fig. 2G), were observed in mouse embryos (Torres-Padilla et al. 2007). Abnormal cell division was also detected in cell lines and embryos, and large and small nuclei were contained in one cell (Supplementary Fig. $2 \mathrm{H}$ and I). The abnormal cell division cannot be detected in cells or embryos treated with DMSO. The results above suggested that CARM1 inhibition can cause abnormal cell division and nuclear organization, which may be the reasons for embryonic developmental retardation.

\section{Silencing Carm 1 reduced developmental potential of mouse blastocyst}

The findings mentioned above revealed that H3R26me2s was catalyzed by CARM1. The H3R26me2s localization was similar with CARM1 expression at the blastocyst stage (Fig. 6A). The CARM1 and H3R26me2s signal levels in the ICM were higher than those in TE. The H3R26me2s signal dramatically weakened, in which the chromatin was condensed (Fig. 6B). The high H3R26me2s signal in the ICM indicated that it may play a specific role in blastocyst development. Considering the CARM1 heterogeneity in early embryos, we explored the role of Carm 1 in mouse embryonic development. We injected Carm 1 siRNA to zygotes to downregulate Carm 1 and then cultured in KSOM medium. We first confirmed Carm 1 knockdown (KD) efficiency using qRTPCR (Supplementary Fig. 3A). As shown in Fig. 6C, the difference in the blastocyst ratio between the siCarm 1injected and control groups was statistically insignificant $(80.7 \pm 2.6 \%$, the control group; $73.7 \pm 4.8 \%$, the siCarm1-injected group). However, blastocyst size in these two groups was significantly variable. Thus, we performed experiments to explore the developmental potential of blastocyst injected with siCarm 1. Then, the 4-day blastocysts were collected for TUNEL assay (Fig. 6D) and anti-CDX2 immunostaining (Fig. 6E). The results showed an apparent increase in apoptotic rates in the siCarm1-injected embryos. The total cell number in siCarm 1-injected blastocysts was apparently reduced. The ICM:TE ratio was also reduced in the siCarm 1injected blastocysts. We then analyzed the expression level of Nanog and Sox17, which are the markers of epiblast and primitive endoderm, respectively. As 

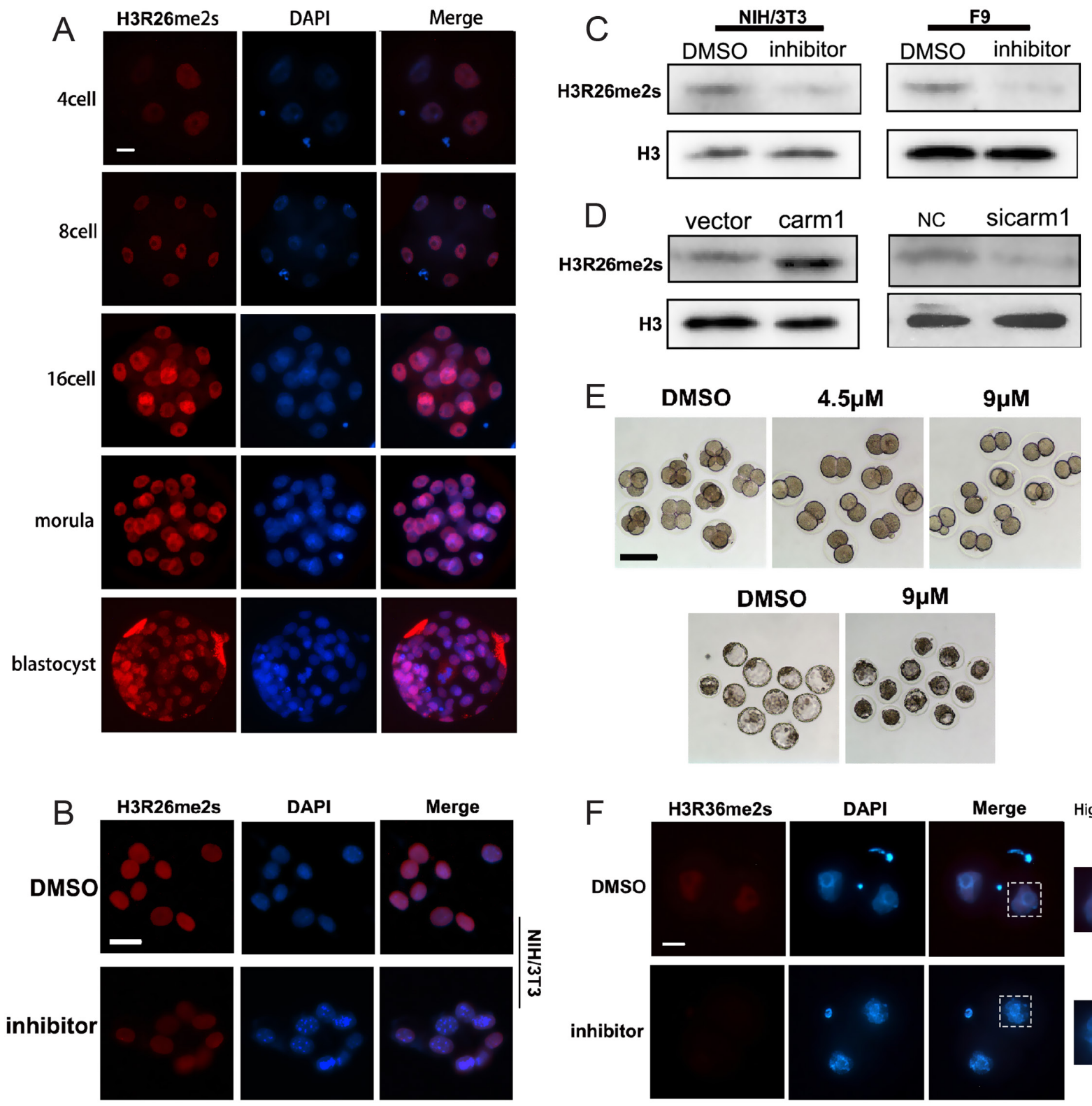

High mag
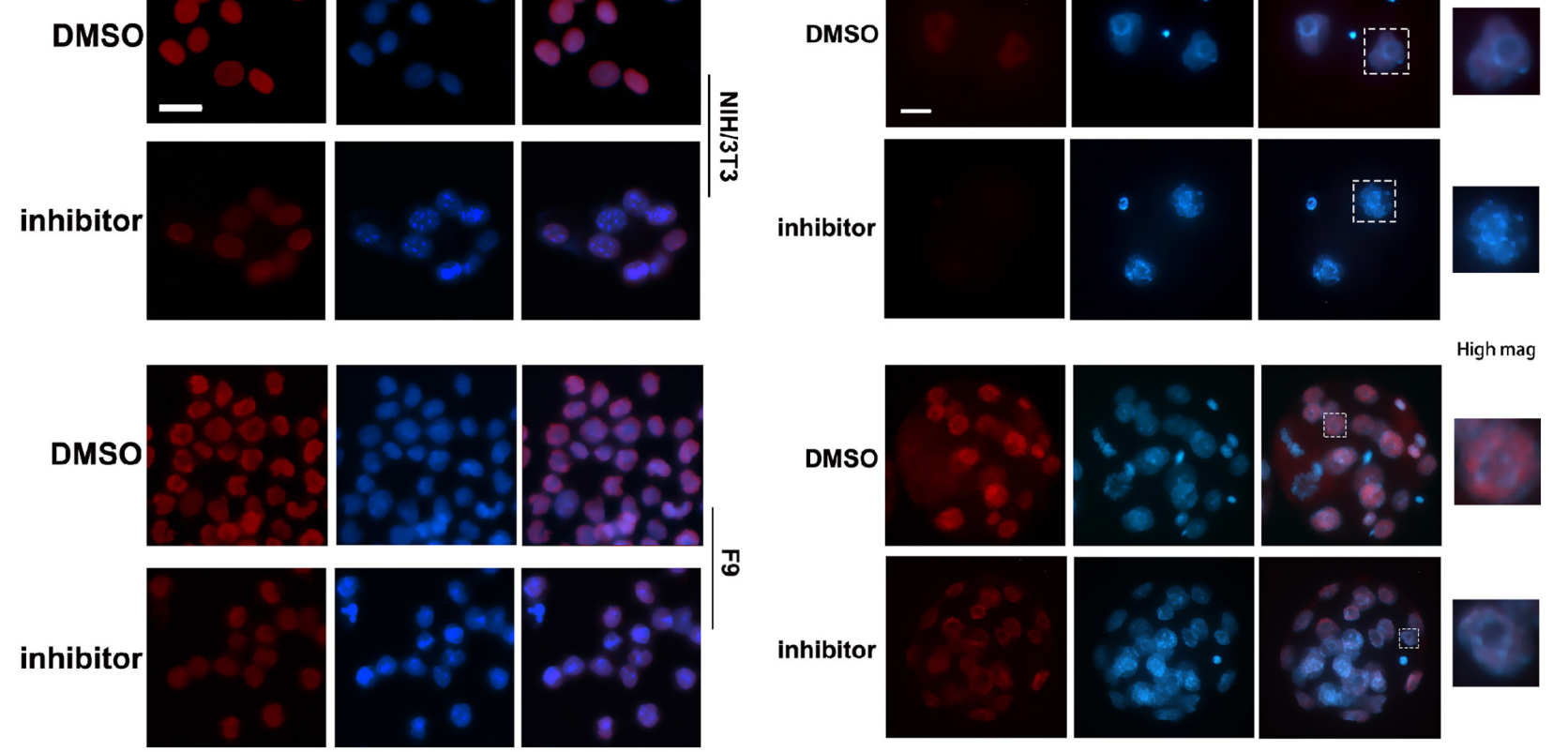

Figure 5 CARM1 was responsible for H3R26me2s construction. (A) Freshly collected early embryos from the four-cell to blastocyst stage were processed for immunostaining with H3R26m2s. Scale bar $=20 \mu \mathrm{m}$. (B and C) H3R26me2s protein levels were determined by immunostaining (B) and immunoblotting $(\mathrm{C})$ in $\mathrm{NIH} / 3 \mathrm{~T} 3$ or F9 cells, which were individually treated with DMSO or CARM1 inhibitor. Scale bar $=10 \mu \mathrm{m}$. (D) H3R26me2 detection in the Carm1 overexpression group and the Carm 1 knockdown group. (E) Developmental arrest was shown when two-cell embryos or morula were cultured in the medium containing CARM1 inhibitor. Scale bar $=100 \mu \mathrm{m}$. (F) H3R26me2s protein levels were determined by immunostaining in embryos treated with DMSO or CARM1 inhibitor. Scale bar $=20 \mu \mathrm{m}$. 

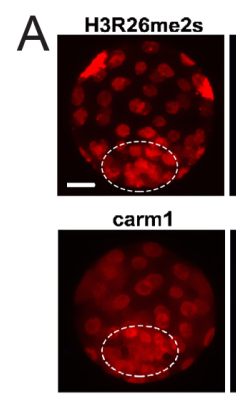

B H3R26me2s
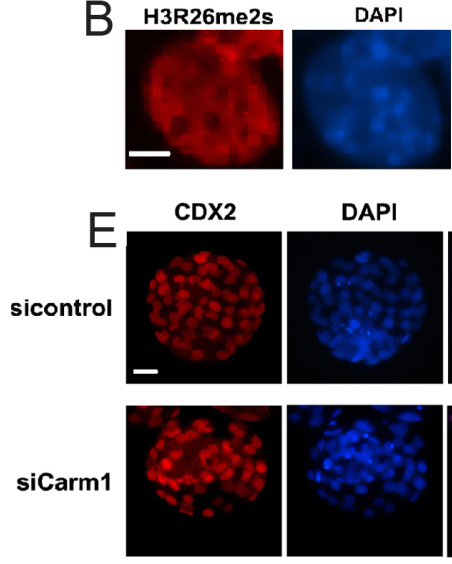

DAPI
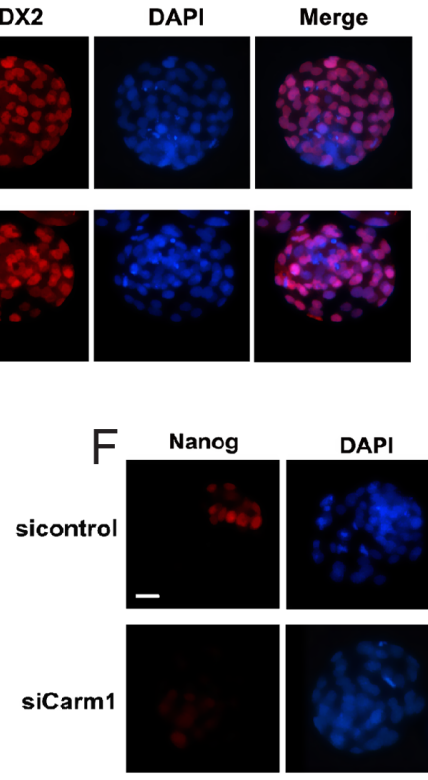

$\mathrm{H}$

siControl

Merge

Merge

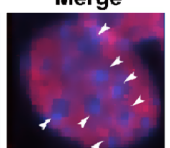

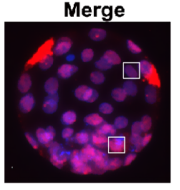
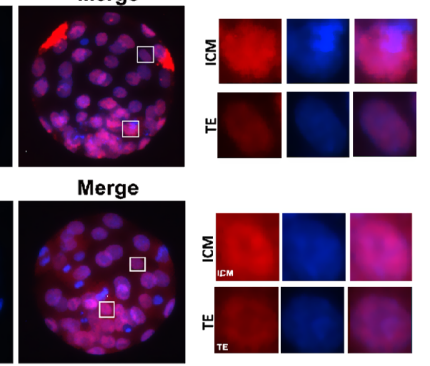

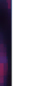
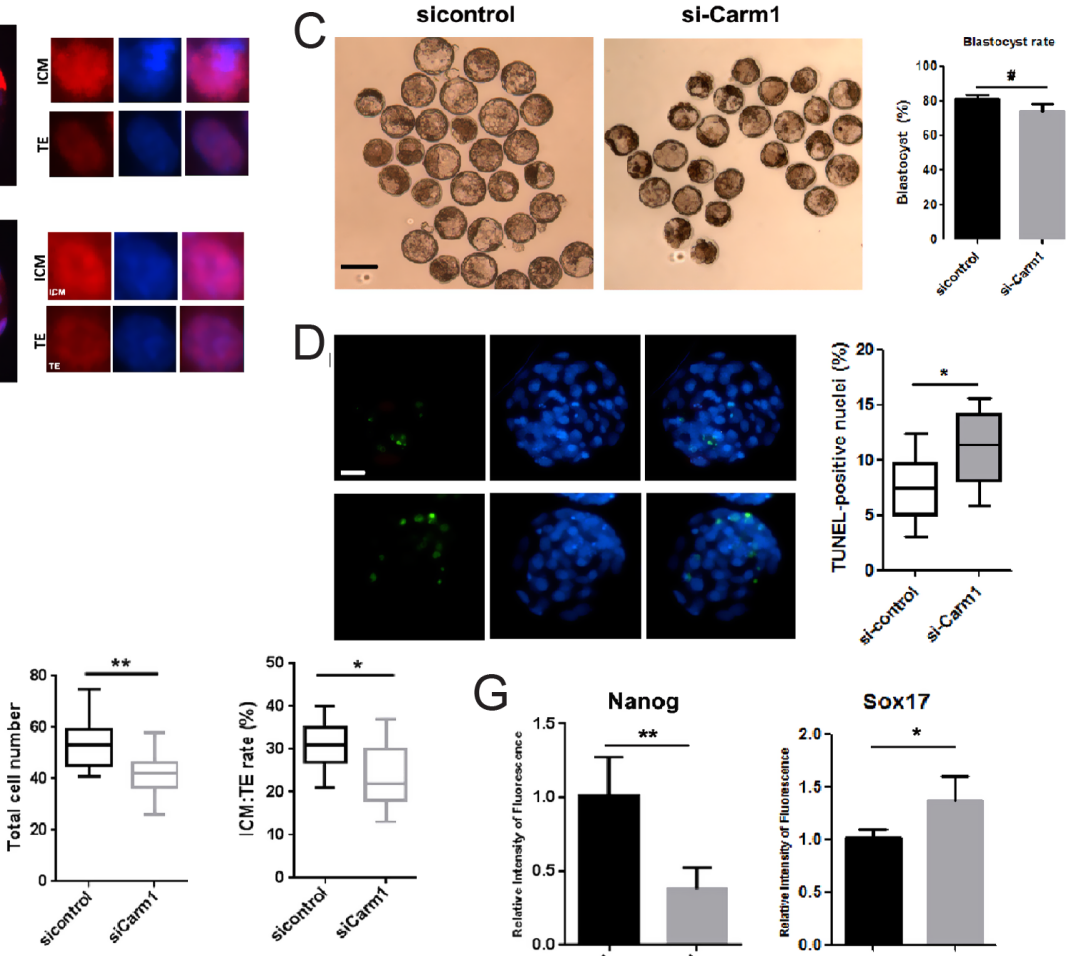

G
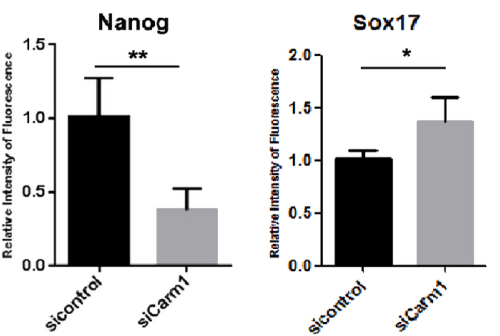

Sox17
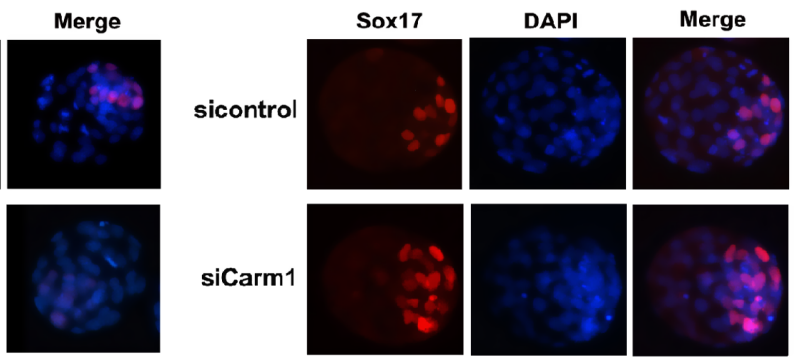

siCarm1

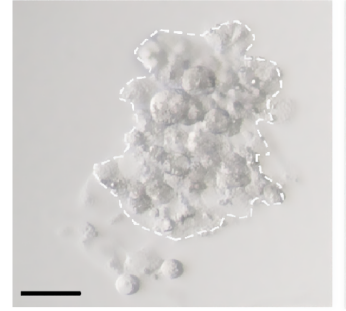

웅

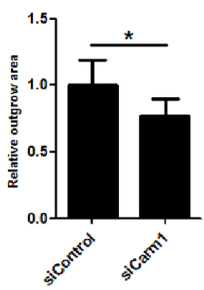

Figure 6 CARM1 was essential for normal blastocyst development. (A) Distribution patterns of CARM1 and H3R26me2s were comparatively determined by immunostaining in blastocyst. Scale bar $=20 \mu \mathrm{m}$. (B) Distribution pattern of H3R26me2s in the nucleus at the blastocyst stage. Scale bar $=2 \mu \mathrm{m}$. (C) Comparison of blastocyst ratio among siCarm 1- $(n=82)$ and siControl-injected embryos $(n=73)$. Scale bar $=100 \mu \mathrm{m}$. Error bars indicate S.D. ${ }^{*} P>0.05$. (D) Representative image of TUNEL-positive cells in mouse blastocysts after injection with siCarm $1(n=10)$ and siControl $(n=9)$. Bars indicate the s.D. ${ }^{*} P<0.05$. (E) CDX2 and DAPI immunostaining in blastocysts developed from siCarm1- $(n=10)$ and siControl-injected groups $(n=10)$. Box plots show the total cell number and ICM:TE ratio of each blastocyst in each group. Scale bar $=20 \mu \mathrm{m}$. Bars indicate the S.D. ${ }^{*} P<0.05,{ }^{* *} P<0.01$. (F) Representative images of Nanog and Sox 17 in mouse blastocysts after injection with siCarm 1 $(n=10)$ and siControl $(n=8)$. Scale bar $=20 \mu \mathrm{m}$. (G) Fluorescence intensities of Nanog and Sox 17 were analyzed and shown as box plots. Bars indicate the S.D. ${ }^{*} P<0.05,{ }^{* *} P<0.01$. (H) Representative image of outgrowth blastocysts treated with DMSO $(n=8)$ or CARM1 inhibitor $(n=8)$. Relative outgrowth area between these two groups is shown as box plot (right panel). Scale bar $=20 \mu \mathrm{m}$. Bars indicate the S.D. ${ }^{*} P<0.05$. 
shown in Fig. 6F and G, Nanog expression level was significantly reduced in siCarm 1 -injected embryos, and the Sox 17 expression level was slightly increased. Then, we collected E4.0 embryos to perform an outgrowth experiment in analyzing the outgrowth potential of embryos, in which Carm 1 was silenced. We collected D4.0 embryos injected with siControl or siCarm 1 individually and cultured the two groups in a stem cell culture medium for 3 days. The capacity for embryos injected with siCarm 1 to initiate spreading over the culture surface was lower than that of the control group (Fig. 6H). Considering the relationship between the H3R26me2s and nuclear organization in early embryos (Supplementary Fig. 2), we explored whether Carm 1 affects the H3K4me3 and H3K9me3 levels, which are closely related to chromatin structure and transcription regulation. As shown in Supplementary Fig. 3B, H3K4me3 level but not H3K9me3 was reduced when CARM1 was inhibited by a CARM1-specific inhibitor, which may be one reason for the change in nuclear organization and transcription imbalance in blastocyst when CARM1 was inhibited.

\section{Discussion}

In this study, the heterogeneous CARM1 distribution at the four-cell stage was not predetermined, and the role of Carm 1 for the further development of blastocyst is important. The following are the basis for this conclusion. (1) CARM1 was heterogeneously distributed at the late four-cell stage, and heterogeneity was not predetermined at the two-cell stage; (2) at the four-cell stage, miR-181a participated in the translation regulation of Carm $1 \mathrm{mRNA}$ and may be one of the regulators for heterogeneous CARM1 protein distribution; (3) CARM1 was responsible for H3R26me2s modification; and (4) CARM1 was important for further blastocyst development (Fig. 7).

The first cell-fate determination in mammalian embryos has gained considerable research interest. In addition, the time the blastomere heterogeneity first arises and how this condition may occur remained debatable to date. The blastomeres of the early mammalian embryo seem to be nearly equivalent in their developmental potency until the generation of the inside and outside cells (Yamanaka et al. 2006,
Rossant \& Tam 2009, Wennekamp et al. 2013). However, molecular heterogeneity is already exhibited in the four-cell stage embryos, thereby showing the differences in developmental potential toward either ICM or TE of the four blastomeres (Piotrowska-Nitsche et al. 2005, Wu et al. 2009, Goolam et al. 2016, White et al. 2016). Meanwhile, two emerging studies have provided new evidence that heterogeneity is identified at the two- to four-cell stage (Hupalowska et al. 2018, Wang et al. 2018). The heterogeneity of CARM1 protein has two seemingly contradictory views. Torres-Padilla et al. (2007) reported that the CARM1 heterogeneity in individual blastomeres first appeared at the four-cell stage, but the most recently published article showed that CARM1 protein showed asymmetric expression at the two-cell stage (Hupalowska et al. 2018). These findings are slightly contradictory. In our experiments, CARM1 was found in the whole blastomere of each embryo stage and showed uniform distribution within the nucleus or cytoplasm. The CARM1 protein distribution in the nucleus was higher than that in the cytoplasm. Thus, the ratio of CARM1 staining in the nucleus and cytoplasm was adopted to analyze the CARM1 protein heterogeneity. Consistent with previous reports by Torres-Padilla et al. (2007), CARM1 protein showed asymmetrical distribution in four-cell stage embryos in our study. However, we found that most embryos which showed heterogeneity in CARM1 distribution were at the late four-cell stage.

In our experiments, the two blastomeres at the fourcell stage with high or low CARM1 protein levels did not show indications that they came from the same two-cell stage embryo blastomere. The two blastomeres with the highest and lowest CARM1 staining can come from one of the blastomeres of the two-cell embryos. In addition, the cell fate decision of the two-cell blastomeres has been controversial (Piotrowska et al. 2001, Chroscicka et al. 2004, Motosugi et al. 2005). According to the results shown in Fig. 3, our findings supported Chróścicka A's research. Both blastomeres of the mouse two-cell embryo have the potential to develop into ICM or TE of the blastocyst (Chroscicka et al. 2004). Considering the above points, CARM1 is heterogeneous at the two-cell stage and can promote ICM formation (Torres-Padilla et al. 2007,

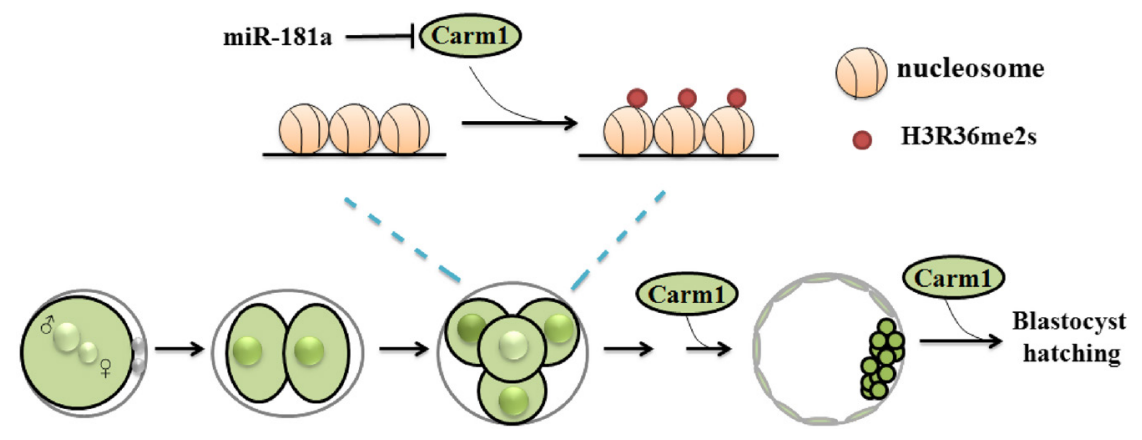

https://rep.bioscientifica.com
Figure 7 Schematic representation of the proposed model illustrating the heterogeneous distribution of CARM1 in preimplantation embryos. In four-cell-stage embryos, miR-181a participates in the expression and distribution of CARM1. In blastocyst stage, CARM1 is highly distributed in ICM and regulates gene expression important for normal blastocyst development. The green color represents the expression level of CARM1. 
Hupalowska et al. 2018). Each two-cell embryo blastomere should have a distinguishable fate in the blastocyst (Piotrowska et al. 2001). This phenomenon seems to be relatively contradictory to our results. We speculated that the research difference has the following possibilities: (1) differences in research methods and analytical methods we mentioned above, (2) differences in mouse strains, and (3) possible varying Carm1 expression level in one blastomere, accompanied with the change in spatial and polarity through embryonic development. Meanwhile, the mRNA level in each blastomere of the four-cell stage also showed heterogeneity. Xu et al. (2013) reported that miR-181c is a Carm 1 regulator. MiR-181c had low expression levels in early embryos (Fig. 4C). Here, our research showed that miR-181a was one of the regulators for Carm 1 expression and heterogeneity in the four-cellstage embryos. When miR-181a was inhibited, the proportion of heterogeneous embryos was dramatically lower than that of the control group (Fig. 4J). To the best of our knowledge, this work is the first time to reveal the regulatory relationship between miRNA and embryo heterogeneity. However, approximately $38 \%$ of embryos were still heterogeneously distributed at the late fourcell stage when miR-181a was inhibited. Thus, other factors may participate in the regulation of CARM1 heterogeneous distribution in the late four-cell stage embryos. Wang et al. (2018) reported LincGET functions as a scaffold to recruit diffusible Carm1 in the nucleus. Hupalowska et al. (2018) reported that the association of the CARM1 with paraspeckles can affect proper lineage allocation in mouse preimplantation embryos. Carm 1 expression and distribution in a four-cell stage blastomere may be regulated by the inherent molecular or CARM1's partner, such as miRNA, IncRNA, and other proteins. However, the exact mechanism and the original effector for the heterogeneity need further investigation.

Histone arginine methylation is a key regulator for cell fate decision in the early mouse embryo, and CARM1 is an asymmetrically arginine methylase. Here, our research showed that CARM1 can also catalyze sDMA formation on H3R26. H3R26me2a, which is a symmetrical dimethylation on H3R26, was also catalyzed by CARM1. The distribution model of H3R26me2a in mouse early embryos was unclear, and the functional difference between these two modifications also needs further studies.

Next, we focused on the effects of Carm 1 on blastocyst developmental quality and potential. Although the blastocyst rate was unaffected, the blastocyst quality in the Carm $1 \mathrm{KD}$ group was worse than that of the control group. Carm1 KD embryos were delayed in their developmental size and formed blastocysts with reduced numbers of cells, in which the abnormal Nanog and Sox17 expression occurred. The outgrowth area was also smaller in the Carm1-silenced group than that of the control group, thereby indicating that the developmental potential cannot be as good as normal embryos when CARM1 was inhibited. Mice with Carm 1 knockout have given birth although this offspring is smaller than wt littermates and died only after birth (Kim et al. 2010). In addition, the evidence we discussed above revealed Carm 1 as an important regulator for cell fate and pluripotency in the early mouse embryo. Thus, Carm 1 may be a full non-essential condition for mouse embryonic development.

Briefly, we elucidated the expression model of Carm 1 in mouse preimplantation embryos and found heterogeneous nuclear distribution of CARM1 at the late four-cell stage. The CARM1 heterogeneity was not predetermined in two-cell embryos. miR-181a was also a key regulator for heterogeneous distribution at the late four-cell stage, and CARM1 was an important protein for mouse preimplantation embryonic development, especially for blastocyst hatching.

\section{Supplementary materials}

This is linked to the online version of the paper at https://doi.org/10.1530/REP-19-0405.

\section{Declaration of interest}

The authors declare that there is no conflict of interest that could be perceived as prejudicing the impartiality of the research reported.

\section{Funding}

This work was funded by the grant (No. 31172279) from the National Natural Science Foundation of China.

\section{Author contribution statement}

Y Z and $\mathrm{HZ}$ S designed and conceived the experiments; $\mathrm{HZ}$ S and J M S conducted the oocyte and embryo manipulations; H Z S, X P X, and J M S conducted the molecular experiments; $\mathrm{H} Z \mathrm{Z}, \mathrm{F} Y \mathrm{~W}$, and J C Z contributed to the bioinformatics analysis; $\mathrm{HZS}$, J K, and YY C conducted the cell manipulations; $\mathrm{Y} Z$ and $\mathrm{HZ}$ S wrote the manuscript, and all authors reviewed the manuscript.

\section{Acknowledgments}

The authors thank all the members of the team for providing technical support and valuable suggestions.

\section{References}

Bedford MT \& Clarke SG 2009 Protein arginine methylation in mammals: who, what, and why. Molecular Cell 33 1-13. (https://doi.org/10.1016/j. molcel.2008.12.013) 
Bedford MT \& Richard S 2005 Arginine methylation an emerging regulator of protein function. Molecular Cell 18 263-272. (https://doi. org/10.1016/j.molcel.2005.04.003)

Chen D, Huang SM \& Stallcup MR 2000 Synergistic, p160 coactivatordependent enhancement of estrogen receptor function by CARM1 and p300. Journal of Biological Chemistry 275 40810-40816. (https://doi. org/10.1074/jbc.M005459200)

Chen LQ, Li Q, Wang J, Jin S, Zheng HM, Lin J, He F, Zhang H, Ma S, Mei J et al. 2017 MiR-29b-3p promotes chondrocyte apoptosis and facilitates the occurrence and development of osteoarthritis by targeting PGRN. Journal of Cellular and Molecular Medicine 21 3347-3359. (https://doi. org/10.1111/jcmm.13237)

Cheng H, Qin Y, Fan H, Su P, Zhang X, Zhang H \& Zhou G 2013 Overexpression of CARM1 in breast cancer is correlated with poorly characterized clinicopathologic parameters and molecular subtypes. Diagnostic Pathology 8 129. (https://doi.org/10.1186/1746-1596-8-129)

Chroscicka A, Komorowski S \& Maleszewski M 2004 Both Blastomeres of the mouse 2-cell embryo contribute to the embryonic portion of the blastocyst. Molecular Reproduction and Development 68 308-312. (https://doi.org/10.1002/mrd.20081)

Cook JR, Lee JH, Yang ZH, Krause CD, Herth N, Hoffmann R \& Pestka S 2006 FBXO11/PRMT9, a new protein arginine methyltransferase, symmetrically dimethylates arginine residues. Biochemical and Biophysical Research Communications 342 472-481. (https://doi. org/10.1016/j.bbrc.2006.01.167)

Dernowsek JA, Pereira MC, Fornari TA, Macedo C, Assis AF, Donate PB, Bombonato-Prado KF, Passos-Bueno MR \& Passos GA 2017 Posttranscriptional interaction between miR-450a-5p and miR-28$5 p$ and STAT1 mRNA triggers osteoblastic differentiation of human mesenchymal stem cells. Journal of Cellular Biochemistry 118 4045-4062. (https://doi.org/10.1002/jcb.26060)

Di Lorenzo A \& Bedford MT 2011 Histone arginine methylation. FEBS Letters 585 2024-2031. (https://doi.org/10.1016/j.febslet.2010.11.010)

Fujimori T, Kurotaki Y, Miyazaki J \& Nabeshima Y 2003 Analysis of cell lineage in two- and four-cell mouse embryos. Development 130 5113-5122. (https://doi.org/10.1242/dev.00725)

Goolam M, Scialdone A, Graham SJL, Macaulay IC, Jedrusik A, Hupalowska A, Voet T, Marioni JC \& Zernicka-Goetz M 2016 Heterogeneity in Oct4 and Sox2 targets biases cell fate in 4-cell mouse embryos. Cell 165 61-74. (https://doi.org/10.1016/j.cell.2016.01.047)

Goossens K, Mestdagh P, Lefever S, Van Poucke M, Van Zeveren A, Van Soom A, Vandesompele J \& Peelman L 2013 Regulatory microRNA network identification in bovine blastocyst development. Stem Cells and Development 22 1907-1920. (https://doi.org/10.1089/scd.2012.0708)

Hamatani T, Carter MG, Sharov AA \& Ko MS 2004 Dynamics of global gene expression changes during mouse preimplantation development. Developmental Cell 6 117-131. (https://doi.org/10.1016/s15345807(03)00373-3)

Hong H, Kao C, Jeng MH, Eble JN, Koch MO, Gardner TA, Zhang S, Li L, Pan CX, Hu Z et al. 2004 Aberrant expression of CARM1, a transcriptional coactivator of androgen receptor, in the development of prostate carcinoma and androgen-independent status. Cancer 101 83-89. (https://doi.org/10.1002/cncr.20327)

Hupalowska A, Jedrusik A, Zhu M, Bedford MT, Glover DM \& ZernickaGoetz M 2018 CARM1 and paraspeckles regulate pre-implantation mouse embryo development. Cell 175 1902-1916.e13. (https://doi. org/10.1016/j.cell.2018.11.027)

Kim J, Lee J, Yadav N, Wu Q, Carter C, Richard S, Richie E \& Bedford MT 2004 Loss of CARM1 results in hypomethylation of thymocyte cyclic AMP-regulated phosphoprotein and deregulated early $\mathrm{T}$ cell development. Journal of Biological Chemistry 279 25339-25344. (https://doi.org/10.1074/jbc.M402544200)

Kim D, Lee J, Cheng D, Li J, Carter C, Richie E \& Bedford MT 2010 Enzymatic activity is required for the in vivo functions of CARM1. Journal of Biological Chemistry 285 1147-1152. (https://doi.org/10.1074/jbc. M109.035865)

Liu WM, Pang RTK, Chiu PCN, Wong BPC, Lao KQ, Lee KF \& Yeung WSB 2012 Sperm-borne microRNA-34c is required for the first cleavage division in mouse. PNAS 109 490-494. (https://doi.org/10.1073/pnas.1110368109)

Ma H, Baumann CT, Li H, Strahl BD, Rice R, Jelinek MA, Aswad DW, Allis CD, Hager GL \& Stallcup MR 2001 Hormone-dependent,
CARM1-directed, arginine-specific methylation of histone $\mathrm{H} 3$ on a steroid-regulated promoter. Current Biology 11 1981-1985. (https://doi. org/10.1016/s0960-9822(01)00600-5)

Motosugi N, Bauer T, Polanski Z, Solter D \& Hiiragi T 2005 Polarity of the mouse embryo is established at blastocyst and is not prepatterned. Genes and Development 19 1081-1092. (https://doi.org/10.1101/ gad.1304805)

O'Brien KB, Alberich-Jorda M, Yadav N, Kocher O, DiRuscio A, Ebralidze A, Levantini E, Sng NJL, Bhasin M, Caron T et al. 2010 CARM1 is required for proper control of proliferation and differentiation of pulmonary epithelial cells. Development 137 2147-2156. (https://doi. org/10.1242/dev.037150)

Osada S, Suzuki S, Yoshimi C, Matsumoto M, Shirai T, Takahashi S \& Imagawa M 2013 Elevated expression of coactivator-associated arginine methyltransferase 1 is associated with early hepatocarcinogenesis. Oncology Reports 30 1669-1674. (https://doi.org/10.3892/ or.2013.2651)

Parfitt DE \& Zernicka-Goetz M 2010 Epigenetic modification affecting expression of cell polarity and cell fate genes to regulate lineage specification in the early mouse embryo. Molecular Biology of the Cell 21 2649-2660. (https://doi.org/10.1091/mbc.E10-01-0053)

Piotrowska K, Wianny F, Pedersen RA \& Zernicka-Goetz M 2001 Blastomeres arising from the first cleavage division have distinguishable fates in normal mouse development. Development 128 3739-3748.

Piotrowska-Nitsche K \& Zernicka-Goetz M 2005 Spatial arrangement of individual 4-cell stage blastomeres and the order in which they are generated correlate with blastocyst pattern in the mouse embryo. Mechanisms of Development 122 487-500. (https://doi.org/10.1016/j. mod.2004.11.014)

Piotrowska-Nitsche K, Perea-Gomez A, Haraguchi S \& Zernicka-Goetz M 2005 Four-cell stage mouse blastomeres have different developmental properties. Development 132 479-490. (https://doi.org/10.1242/ dev.01602)

Renthal NE, Chen CC, Williams KC, Gerard RD, Prange-Kiel J \& Mendelson CR 2010 miR-200 family and targets, ZEB1 and ZEB2, modulate uterine quiescence and contractility during pregnancy and labor. PNAS 107 20828-20833. (https://doi.org/10.1073/ pnas.1008301107)

Rossant J \& Tam PP 2009 Blastocyst lineage formation, early embryonic asymmetries and axis patterning in the mouse. Development 136 701-713. (https://doi.org/10.1242/dev.017178)

Schurter BT, Koh SS, Chen D, Bunick GJ, Harp JM, Hanson BL, HenschenEdman A, Mackay DR, Stallcup MR \& Aswad DW 2001 Methylation of histone $\mathrm{H} 3$ by coactivator-associated arginine methyltransferase 1 . Biochemistry 40 5747-5756. (https://doi.org/10.1021/bi002631b)

Sims 3rd RJ, Rojas LA, Beck DB, Bonasio R, Schuller R, Drury 3rd WJ, Eick D \& Reinberg D 2011 The C-terminal domain of RNA polymerase II is modified by site-specific methylation. Science 332 99-103. (https:// doi.org/10.1126/science.1202663)

Sinkkonen L, Hugenschmidt T, Berninger P, Gaidatzis D, Mohn F, ArtusRevel CG, Zavolan M, Svoboda P \& Filipowicz W 2008 MicroRNAs control de novo DNA methylation through regulation of transcriptional repressors in mouse embryonic stem cells. Nature Structural and Molecular Biology 15 259-267. (https://doi.org/10.1038/nsmb.1391)

Su JM, Wang YS, Li RZ, Peng H, Hua S, Li Q, Quan FS, Guo ZK \& Zhang Y 2012 Oocytes selected using BCB staining enhance nuclear reprogramming and the in vivo development of SCNT embryos in cattle. PLOS ONE 7 e36181. (https://doi.org/10.1371/journal.pone.0036181)

Sun H, Kang J, Su J, Zhang J, Zhang L, Liu X, Zhang J, Wang F, Lu Z, Xing $X$ et al. 2018 Methionine adenosyltransferase 2A regulates mouse zygotic genome activation and morula to blastocyst transition. Biology of Reproduction 100 601-617. (https://doi.org/10.1093/biolre/ ioy 194)

Tan K, Wang XD, Zhang ZN, Miao K, Yu Y, An L \& Tian JH 2016 Downregulation of miR-199a-5p disrupts the developmental potential of in vitro-fertilized mouse blastocysts. Biology of Reproduction 9554. (https://doi.org/10.1095/biolreprod.116.141051)

Tang F, Kaneda M, O'Carroll D, Hajkova P, Barton SC, Sun YA, Lee C, Tarakhovsky A, Lao KQ \& Surani MA 2007 Maternal microRNAs are essential for mouse zygotic development. Genes and Development 21 644-648. (https://doi.org/10.1101/gad.418707) 
Torres-Padilla ME, Parfitt DE, Kouzarides T \& Zernicka-Goetz M 2007 Histone arginine methylation regulates pluripotency in the early mouse embryo. Nature 445 214-218. (https://doi.org/10.1038/nature05458)

Wang J, Wang L, Feng G, Wang Y, Li Y, Li X, Liu C, Jiao G, Huang C, Shi J et al. 2018 Asymmetric expression of LincGET biases cell fate in two-cell mouse embryos. Cell 175 1887.e18-1901.e18. (https://doi. org/10.1016/j.cell.2018.11.039)

Wennekamp S, Mesecke S, Nedelec F \& Hiiragi T 2013 A self-organization framework for symmetry breaking in the mammalian embryo. Nature Reviews: Molecular Cell Biology 14 452-459. (https://doi.org/10.1038/ nrm3602)

White MD, Angiolini JF, Alvarez YD, Kaur G, Zhao ZW, Mocskos E, Bruno L, Bissiere S, Levi V \& Plachta N 2016 Long-lived binding of Sox 2 to DNA predicts cell fate in the four-cell mouse embryo. Cell 165 75-87. (https://doi.org/10.1016/j.cell.2016.02.032)

Wu Q, Bruce AW, Jedrusik A, Ellis PD, Andrews RM, Langford CF, Glover DM \& Zernicka-Goetz M 2009 CARM1 is required in embryonic stem cells to maintain pluripotency and resist differentiation. Stem Cells 27 2637-2645. (https://doi.org/10.1002/stem.131)

Xu W, Chen H, Du K, Asahara H, Tini M, Emerson BM, Montminy M \& Evans RM 2001 A transcriptional switch mediated by cofactor methylation. Science 294 2507-2511. (https://doi.org/10.1126/ science.1065961)

Xu Z, Jiang J, Xu C, Wang Y, Sun L, Guo X \& Liu H 2013 MicroRNA-181 regulates CARM1 and histone arginine methylation to promote differentiation of human embryonic stem cells. PLOS ONE 8 e53146. (https://doi.org/10.1371/journal.pone.0053146)

Xu C, Zhang Y, Zheng H, Loh HH \& Law PY 2014 Morphine modulates mouse hippocampal progenitor cell lineages by upregulating miR-181a level. Stem Cells 32 2961-2972. (https://doi.org/10.1002/stem.1774)

Yadav N, Lee J, Kim J, Shen J, Hu MC, Aldaz CM \& Bedford MT 2003 Specific protein methylation defects and gene expression perturbations in coactivator-associated arginine methyltransferase 1-deficient mice. PNAS 100 6464-6468. (https://doi.org/10.1073/pnas.1232272100)

Yadav N, Cheng D, Richard S, Morel M, Iyer VR, Aldaz CM \& Bedford MT 2008 CARM1 promotes adipocyte differentiation by coactivating
PPARgamma. EMBO Reports 9 193-198. (https://doi.org/10.1038/ sj.embor.7401151)

Yamanaka Y, Ralston A, Stephenson RO \& Rossant J 20062006 cell and molecular regulation of the mouse blastocyst. Developmental Dynamics 235 2301-2314. (https://doi.org/10.1002/dvdy.20844)

Zhang Q, Sun HX, Jiang Y, Ding LJ, Wu SG, Fang T, Yan GJ \& Hu YL 2013 MicroRNA-181a suppresses mouse granulosa cell proliferation by targeting activin receptor IIA. PLOS ONE 8 e59667. (https://doi. org/10.1371/journal.pone.0059667)

Zhang JQ, Wang Y, Liu XG, Jiang SL, Zhao C, Shen R, Guo XR, Ling XF \& Liu C 2015 Expression and potential role of microRNA-29b in mouse early embryo development. Cellular Physiology and Biochemistry 35 1178-1187. (https://doi.org/10.1159/000373942)

Zhang Z, Nikolai BC, Gates LA, Jung SY, Siwak EB, He B, Rice AP, O'Malley BW \& Feng Q 2017 Crosstalk between histone modifications indicates that inhibition of arginine methyltransferase CARM1 activity reverses HIV latency. Nucleic Acids Research 45 9348-9360. (https:// doi.org/10.1093/nar/gkx550)

Zhang LL, He XY, Li F, Pan H, Huang XL, Wen XY, Zhang H, Li B, Ge SF, Xu XF et al. 2018 The miR-181 family promotes cell cycle by targeting CTDSPL, a phosphatase-like tumor suppressor in uveal melanoma. Journal of Experimental and Clinical Cancer Research 37 15. (https://doi. org/10.1186/s13046-018-0679-5)

Zhao HY, Zhang YJ, Dai H, Zhang Y \& Shen YF 2011 CARM1 mediates modulation of Sox2. PLOS ONE 6 e27026. (https://doi.org/10.1371/ journal.pone.0027026)

Received 29 August 2019

First decision 10 September 2019

Revised manuscript received 15 October 2019

Accepted 12 November 2019 